\title{
Factors Influencing Students' Decision to Drop Out of Online Courses in Brazil
}

\author{
Isabella Moreira Pereira de Vasconcellos ${ }^{1}$, Diogo Tavares Robaina ${ }^{1} \&$ Carole Bonanni $^{2}$ \\ ${ }^{1}$ ESPM-Rio, Rio de Janeiro, Brazil \\ ${ }^{2}$ ESC- Rennes Business School, France \\ Correspondence: Isabella Moreira Pereira de Vasconcellos, ESPM-Rio, Rio de Janeiro, Brazil. E-mail: \\ ivasconcellos@espm.br
}

Received: August 24, 2020 Accepted: September 26, 2020 Online Published: September 30, 2020

doi:10.5539/jel.v9n5p284 URL: https://doi.org/10.5539/jel.v9n5p284

\begin{abstract}
In recent years, e-learning has been the fastest growing educational form in students' numbers, and this industry's market revenue (Lee, Choi, \&Kim, 2013).

Despite this growth, concern about the significantly higher student dropout rate of students in online courses as compared with conventional learning environments has increased. Brazil has also registered a significant increase in the number of students interested in this type of education, but the dropout rate is a considerable concern to institutions.

This study's objective was to identify the relevant variables behind online students' dropout decision in Brazil. After a literature review that determined the ten most recurrent and relevant variables, we heard professional e-learning experts. They indicated, from their standpoint, what the most pertinent variables influencing dropout would be. Based on this, we conducted a quantitative survey with e-learning students, considering the factors indicated in the literature on this subject and educational professionals' indications.

This study's contribution was to verify that the quality support is extraordinarily relevant and has a high correlation with students' perception of Usefulness, the quality of Course Content, and ease of System Use.
\end{abstract}

Keywords: e-learning, dropout, support quality, information quality, system quality, course usefulness

\section{Introduction}

The rise of e-learning offerings and demand in Brazil has increased institutions' concern about student dropout rates. This study aims to identify factors influencing students' decision to drop out of online courses in Brazil.

The analysis proposes an e-learning model based on the literature review and a discussion with e-learning monitors, executives, and experts, who indicated the dropout rate's primary influencers. A quantitative survey occurred with e-learning students, using the variables indicated by the experts and the literature.

This study's theoretical contribution is combining theories from different research fields, including learning psychology, TAM and System, and Information (IS) failure. The proposed model addresses technical aspects, including the Information system success model (DeLone \& McLean, 2003), the Technology Acceptance Model (Davis, 1980), and students' psychological aspects. It also contemplates the cultural dimension (Hoststade, 2001b) intrinsic to the learning style. In the model, service quality refers to teacher and tutor support to students, and it has a moderating effect on the perception of the system, information quality, and Perceived Usefulness.

The experts indicated cultural aspects as influencers in the learning style and, consequently, to drop out. As Brazil and Brazilian culture present some specific characteristics, which could affect some of the dropout factors, it became relevant to consider the cultural dimension.

Based on Hofstede's (1980) study that differentiates culture from the perspective of individualism/collectivism, this cultural dimension is associated with students' learning styles and how they perceive performance.

Aparicio et al. (2016b) reported that the level of individualism/collectivism contributes positively to individual impact reflecting on students' perception of performance effectiveness from the e-learning system. Hofstede's study (2001a) states that individualism is strongly associated with technology adoption, which can be important 
in an e-learning environment affecting students' performance.

\section{Methodology, Philosophy, and Approach}

In the literature review, we found six recurring variables influencing dropout: Perceived Usefulness, Learning Style, Academic Goal Commitment, System Failure, Information Failure, and Support Quality.

After the discussion with 12 e-learning experts, including professors and quality managers and monitors who work for the three principal educational providers in the E-learning Business, we added learning style and Perceived Usefulness to the model, indicated by them as factors influencing the dropout rate. We adapted Aparicio, Bacao and Oliveira's (2017) model, and we performed a quantitative survey with 412 respondents, testing these six variables.

As a contribution from a theoretical perspective, the literature review focused on combining theories from different fields, including individual characteristics (goal commitment and learning style); Institution support (support quality); The impact of Information System Failures (Information and System Failure), and Technology Acceptance Model (Usefulness).

\section{Insights from the Discussion with E-Learning Experts}

As most of the researchers focused their studies on students, we found it valuable to analyze dropout reasons from another perspective. The analysis brought together twelve different executives, including tutors, product managers, and managers responsible for the quality and retention of online students of three well-known institutions ranked among the five largest educational institutions offering online courses with 210,000 online students. Based on the variables identified in the literature, we developed a semi-structured guideline with nine open-ended questions. This discussion allowed us to explore the reasons for dropout reasons from an executive point of view. The variables identified as the main reasons for the dropout decision were: Usefulness, Learning Style, Academic Goal Commitment (emphasis on self-discipline), Information Failure, System Failure, and Support Quality.

These discussions led to the construction and testing of a revised framework based on the Aparicio, Bacao and Oliveira (2017) model, which already considered the variables of Academic Goal Commitment, Information Failure, System Failure, and Support Quality. The revision of prior studies and the inputs from the experts' interview suggested the use of support quality as a moderator variable affecting the perception of system and information quality and perceived Usefulness. The variables of learning style and Perceived Usefulness were added to Aparicio, Bacao and Oliveira's (2016a) model based on experts' discussion and Brazilian cultural aspects. The experts emphasized the importance of tutors supporting students with system problems and professors' role supporting students in the online environment and bringing their professional experience to the classes, emphasizing the Usefulness of the content.

We then applied a quantitative study at the most significant online educational institution.

Gathering all these factors in a model to be tested in Brazil is another theoretical and empirical contribution. The combination of students' and experts' perceptions as the main reasons for dropping out is a gap in the literature, filled with this study. Thus, the revised model contemplates the following variables: Usefulness, Learning Style, Academic Goal Commitment, Information Failure, System Failure, and Support Quality.

This study considered students registered in short non-credit courses open to the general public, lasting eight weeks. A total of Four hundred twelve students answered the questionnaire.

\section{Theoretical Framework and Methods}

The literature review had the purpose of identifying the most recurrent variables influencing e-learning dropout.

The analyses of dropout in the onsite environment began with Spady (1971), and Tinto (1975) considered references in this subject, and the analysis went up to Bean and Eaton (1995). In the online environment, we began analyzing the Davis, Bagozzi, and Washaw's (1989) study, and the review went up to Moore (2014).

E-learning definition

In the beginning, the term "Distance learning" was coined by Guri-Rozenblit (2005), referring to the use of different methodologies to deliver students access to a course content remotely. Initially, its main characteristic was the physical distance between teachers and students (Garrison, 1987). Over the years, the delivery methodology spanned the mail, radio, and television eras and continues today the internet's age, the mainstream vehicle for online courses (Levy, 2007). This new era brought the term E-learning or online learning (Tynan \& James, 2013), offering education or training courses to access course content off-campus and apply Information 


\section{Communication Technology (ICT).}

\subsection{Dropout Definition}

The definition of dropout can have different meanings. A student dropout (or non-completer) can be any student leaving his or her institution of initial enrollment (Spady, 1971) or those deciding to withdraw from e-learning courses (Haydarov, Moxley, \& Anderson, 2013; Levy, 2007). Levy (2007) defined dropout students as those who voluntarily withdraw, incurring financial penalties. Those opting to drop a course during the "add/drop period" are not considered "non-completers" because their tuition is fully refunded.

Bean (1979) used the term attrition to refer to students who leave an institution without completing a given program. Attrition represents a reduction in the number of students remaining enrolled during the reported calendar year. The attrition rate includes dropouts who are either students withdrawing themselves from the program or those dismissed from the university's program.

The attrition rate includes students who may be in good academic standing but did not enroll in the reporting year (Haydarov, Moxley, \& Anderson, 2013).

For this study, the concept of dropout students or non-completers (Levy, 2007) refers to all students not completing a particular course or leaving voluntarily without reaching the goals of an e-learning course, for whatever reason. Dropout is the difference between the number of students enrolling in a course during the base calendar year and those completing the course. This study focuses on course dropout and not program dropout and considers only the students' voluntary withdrawal decision. Forced dropout, decided by the institution, due to low grades or failure, was not recognized as a student-motivated dropout decision.

\subsection{Goal Commitment}

Eskreis-Winkler et al. (2014) studied the effect of goal commitment or passion and perseverance for long-term goals on the retention of students in high school. The Academic goal commitment refers to the ability to work independently, maintain motivation, sustain focus on personal and academic goals, and maintain motivation even when they have other life commitments despite conflicting commitments (Holder, 2007). A student's academic goal commitment is a significant and robust predictor of an intention not to drop out. Students with high academic goal commitment were less likely to drop out of high school (Strom \& Savage, 2014).

It is a direct influencer of dropout decisions (Tinto, 1975; Pascarella \& Terenzini, 1980), and a significant and robust predictor of an intention not to drop out. Students must be motivated to attend an e-learning course. Goal Commitment can have different motivational facets. Student motivation can be Intrinsic when involved with the activity; its enjoyment affects the students' study approach. Extrinsic factors referring to the search for external approval of recognition and their level of commitment to attaining some specific goal are also motivational elements (Lepper, 1988). The intrinsic motivation is particularly important for non-traditional students, most of them adults, because they consider the relevance of skills and subject matter to their career and life goals (Kember, 1989).

\subsection{Learning Style}

In the literature review, the learning style was considered relevant to students' decision to persist or drop out (Rovai, 2003; Willging \& Johnson, 2004; Holder, 2007; Hart, 2012; Lee, Choi, \& Kim, 2013; Moore, 2014). Learning Style supports learners' self-discipline, self- motivation, and responsibility (Kerka, 1996 apud Rovai 2003, p. 11).

Aparicio et al. (2017) have proven that student energy and vigor inherent to their learning style can affect individual performance and e-learning success. The study gathered the student's psychological characteristics of Grit, defined by Duckworth et al. (2007) as the intrinsic personal motivation to persist and pursue long-term objectives and information system variables. Rovai's Composite Persistence Model (2003) highlights the direct effect of internal factors such as learning style, goal commitment, and self-esteem on the decision to persist.

Holtbrügge and Mohr's (2010) findings showed that individuals' cultural values affect their learning style preferences. In the same way, Guild (1994) states that culture can facilitate the learning process.

As the online offering format tends to be globalized, a different cultural background can affect students' satisfaction and decision to persist or drop out of the course. Kizilcec and Halawa (2015) compared dropout in online learning in different geographic areas. They found substantial differences in their level and grade performance among students in two different region groups (Latin America, Asia, and Africa) than the second group of countries (North America, Oceania, and Europe). Online students in the first group were only half as likely to persist, and they presented substantially lower grades than those in the second group. 
As the research took place in Brazil, we considered it relevant to include this variable in the model, considering the possible links between the culture and learning style.

Brazilian culture has some peculiar characteristics as compared to other countries (Hofstade et al., 2010; Schwartz \& Tamayo, 2012; DaMatta, 1984; Chu \& Wood Jr, 2008; Motta \& Alcadipani, 1999; Barros \& Prates, 1996; Almeida, 2014; Pasquali \& Alves, 2004; Teixeira et al., 2014).

Culture can influence people's values, motivational factors, personal goals, and determination to reach them (Teperino et al., 2006; Kizilcec \& Halawa, 2015; Bandura, 2001). People's behavior is a consequence of social system influence sharply defined by culture. It can predict human behavior, influence their judgment regarding their capabilities, and focuses on goals (Bandura, 2001).

The growth in e-learning business across borders, attracting students from different countries and cultures has brought some concern on which format would best serve the different learning styles. The search for a one-size-fits-all model is a challenge; however, the convergence of education systems seems to be more necessary to participate in the globalization of educational institutions, especially in the e-learning format, which is not affected by the country's borders.

As culture can influence learning style, it is relevant to consider cultural aspects and Brazilian culture's specificities.

\subsection{Support Quality}

The main variables of e-learning are human beings and tutors, and they still have an essential role in engaging and motivating students, even on a technological platform (Nerguizina et al., 2010).

Support quality may be related to practical assistance with technology and computer (Hart, 2012) and to pedagogical support influencing how learning and teaching should be delivered considering interaction, collaboration, and communication between learners and teachers in the e-learning environment (Masoumi \& Lindström, 2012).

Although technical support does not predict persistence, dropout students present a lower satisfaction rate with support services (Ivankova \& Stick, 2007). Students may have different levels of computer skills, and tutorial support may be helpful. As in the online environment, there is isolation from faculty; this issue could be addressed, ensuring personal tutors' support. In the e-learning environment, support quality may encourage students to use the system because it provides willingness and attention to address students' difficulty (Aparicio et al., 2017).

As students may face different problems in online platforms, the effectiveness of the support can affect student perception of quality, which is critical for academic success and retaining students. The majority of students reported support quality as one of the most critical factors in persisting (Bunn, 2004).

TAM Model applied toE-Learning Davis' (1989) Technology Acceptance Model (TAM) had the goal to explain the determinants of computer acceptance and their influence on user behavior.

TAM confirms that perceived Usefulness is of primary relevance for computer acceptance behavior. Perceived Usefulness had a significant effect on the intention to use the computer. The TAM-Technology Acceptance Model (Davis, 1989) refers to identifying inhibitors to technology usage intention, an essential element in the e-learning environment.

\subsection{Perceived Usefulness}

Students perceive the Usefulness of online courses as the practical value or utility and relate it to the Intent to leave. This factor, previously indicated as an essential element to retain traditional students (Bean, 1979), was also confirmed as a critical variable in the online dropout decision (Davis, Bagozzi, \& Warchaw, 1989). Perceived Usefulness strongly influences people's intentions to accept computer system usage. Students believe that education used advantageously will lead to self-development, employment, or better job performance (Davis, Bagozzi, \& Warshaw, 1989; Bean, 1979; Davis, 1989).

\subsection{System Failure}

System design can be a big issue for e-learning if students do not get what they desire from the course or have to put more effort than expected, generating dissatisfaction (Chee-Wee Tan, Benbasat, \& Centefelli, 2016). System quality, including responsiveness and reliability of response, can be inhibitors and have a negative and higher impact on technology usage intention (Cenfetelli \& Schwarz, 2011; Willging \& Johnson, 2004). There are statistically significant differences between completers and the dropout group (Holder, 2007). Some of them 
affect dropout decisions such as Lack of student technical preparation, computer skills (Hart, 2012), Internet self-confidence, a de-personalized learning environment, and Lack of support from the professional staff (Willging \& Johnson, 2004).

A lack of IT skills associated with technical problems is an important element and may confuse students and make it hard for them to understand (Rovai, 2003; Packham et al., 2004; Park, 2007).

\subsection{Information Failure}

Information failure, including content and course design, has a high correlation with student satisfaction, and inaccurate or irrelevant information increases dissatisfaction (Chee-Wee Tan, Benbasat, \& Centefelli, 2016). Information failure, its lack of completeness and accuracy, can harm technology usage intention (Cenfetelli \& Schwarz, 2011).

\section{Research Model and Hypotheses}

The discussions with professors, tutors, and experts contributed significantly to analyzing the factors influencing dropout. The professionals reinforced the influence of variables already mentioned by the students in previous surveys as substantial influencing factors in the dropout decision. The discussions were even more relevant when they added the Learning Style variable to the dropout study as a factor in the students' culture. The observation of the professionals was also relevant concerning the effect of Support Quality of professors and tutors on students' perception of Usefulness and practicality of the course on their professional lives, the effect of the quality of this support on the perception of difficulty using the system (System Failure) and also on the perception of course content quality (Information Failure). It seemed important to bring together a single model, the variables identified as being relevant by instructors, mentors, and experts in online learning, recurring variables mentioned in the literature review. Therefore, based on this objective, we tested Aparicio, Bacao and Oliveira's model (2017), adapting to the set of variables indicated by students, professors, and experts, as influencers of dropout.

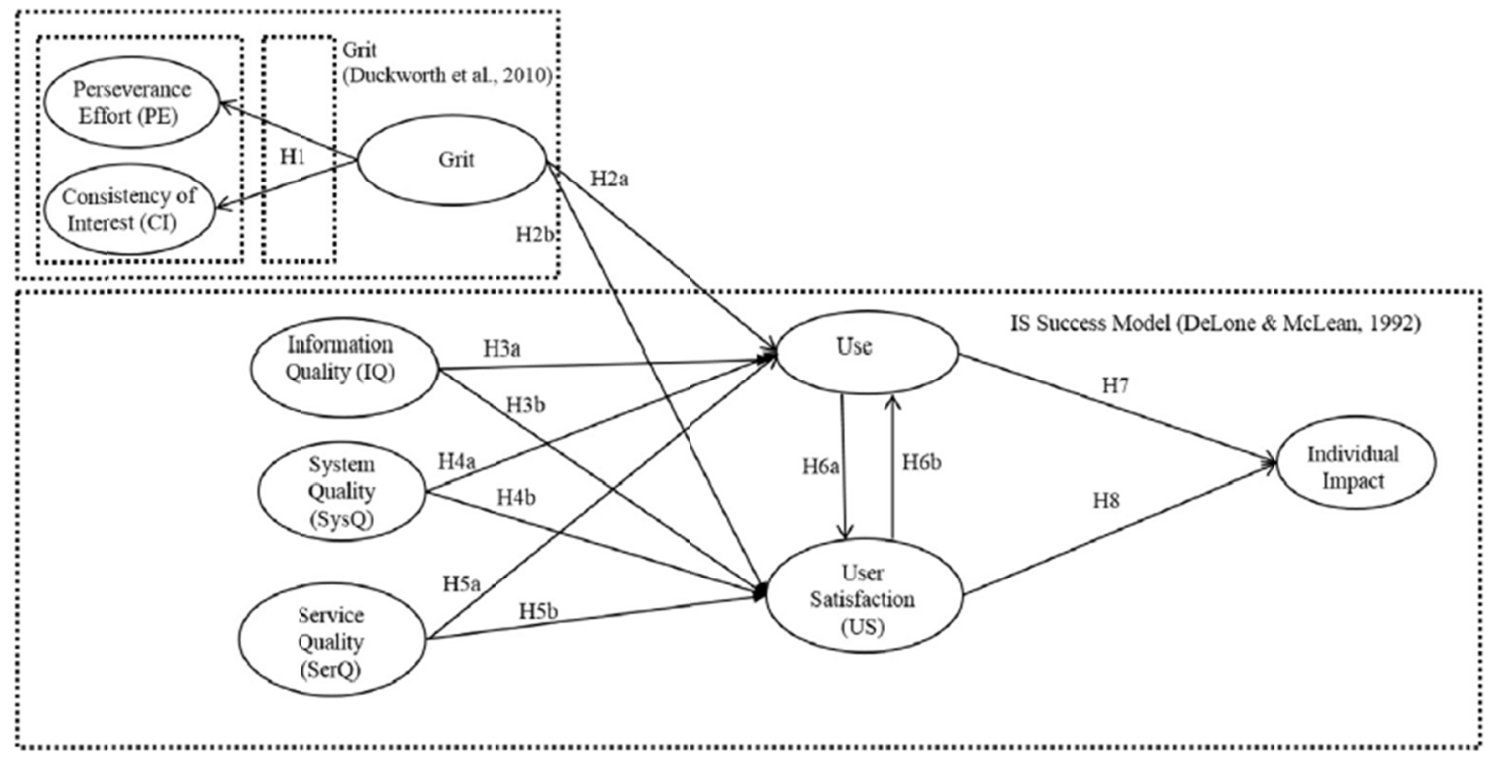

Figure 1. Aparicio, Bacao and Oliveira's original model (2017)

In their model, they relate Information quality, System quality, Grit, and Service quality to the use and satisfaction using e-learning. They defined Grit as self-determination, persistence, and motivation to achieve goals. Their definition matches the Eskreis-Winkler et al. (2014) description who studied the effect of goal commitment or passion and perseverance for long-term goals on high school students' retention. Grit, or academic goal commitment (Holder, 2007), refers to the ability to maintain motivation, sustain focus on personal and academic goals, and maintain motivation.

After considering the six variables indicated by professors, experts, and monitors, we added to Aparicio, Bacao 
and Oliveira's model two variables. The first one was Usefulness indicated by experts and literature review as an essential element to students' persistence. The second variable was Learning style highlighted by experts who had the chance to compare Brazilian and international students behaved in the e-learning environment.

Also, the variable of Support quality, which was already a part of the authors' model, was listed as a moderating variable to the constructs of Information Failure, System Failure, and Perceived Usefulness, based on the experts' analysis. We tested the framework below (Figure 2), compiling all the literature review contributions and discussions with instructors and experts.

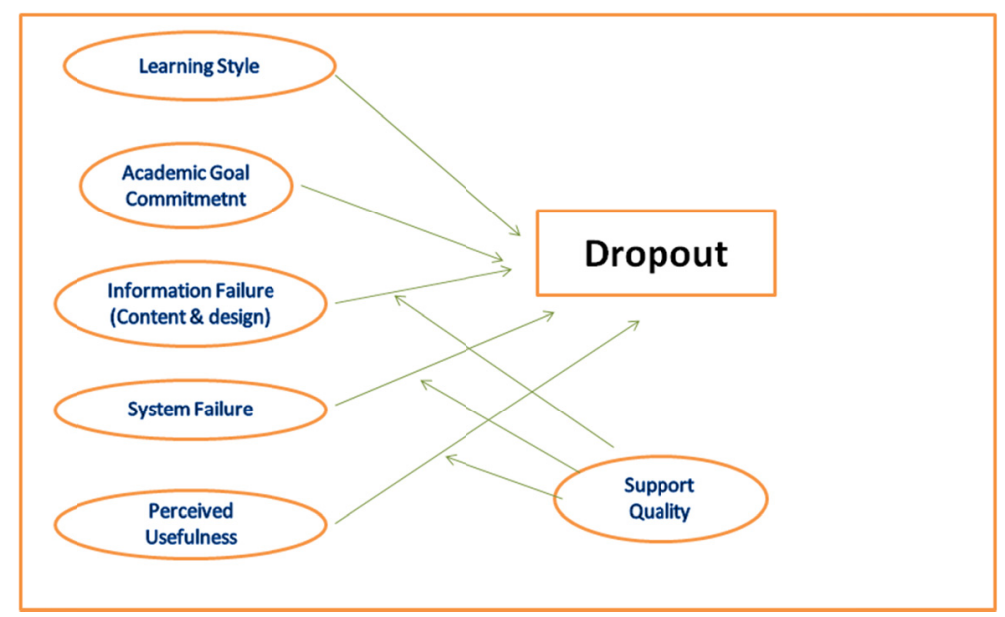

Figure 2. Framework tested

\section{Hypothesis}

HYPOTHESIS (H1) — Learning Style will have a significant influence on the dropout decision.

HYPOTHESIS (H2) - Academic Goal Commitment will have a significant influence on the dropout decision.

HYPOTHESIS (H3) - Information Failure will have a significant influence on the dropout decision.

HYPOTHESIS (H4) - System Failure will have a significant influence on the dropout decision.

HYPOTHESIS (H5) - Perceived Usefulness will have a significant influence on the dropout decision.

HYPOTHESIS (H6) - The support quality will significantly influence the perception of System Failure Information.

HYPOTHESIS (H7) - The support quality will significantly influence the perception of Information Failure.

HYPOTHESIS (H8) - The support quality will significantly influence the Perceived Usefulness of online courses.

\section{Empirical Methodology}

To measure the correlation between dropout-related variables and the influence of support quality as a moderating variable on the perception of Usefulness, Information, and System Failure by students, we used the SEM-Structural Equation Modeling method the Smart PLS tool (Ringle, Wende, \& Becker, 2015).

The SEM tool provides confirmatory statistical analysis and combines regression of a multivariate model with factorial analysis. The margin of error was $4.83 \%$.

\subsection{Data Collection}

The research used primary data analysis and the electronic survey method (Google doc), and it took place between April and June 2019. An email with the questionnaire link was sent directly by the institution with the questionnaire link to the 10,000 students registered in short non-credit courses open to the general public. These courses last eight weeks, and the institution operates nationally and is among the top five players in online course offerings. The analysis considered 412 questionnaires, and 175 students (42.4\%) stated that they had dropped out of the course before finishing. This index ratifies the data history collected by the institution in the last two years. 
An extensive questionnaire consisted of 37 questions focusing on control variables and independent constructs. Students rated each item on a five-point Likert scale ranging from "Strongly Disagree" to "Strongly Agree".

At the end of the questionnaire, three open questions asked the students to share their personal experience with the online course they dropped out.

Cronbach's Alpha used to measure internal consistency indicates how closely related sets of items are grouped. Except for the Academic Goal and Learning Style variables, the other variables presented a reliability coefficient of .70 or higher, which is considered "acceptable" in most social science research situations.

Table 1. Alpha Cronbach

\begin{tabular}{llllllll}
\hline & $\begin{array}{l}\text { academice } \\
\text { goal }\end{array}$ & dropout & learning style & $\begin{array}{l}\text { quality of } \\
\text { online course } \\
\text { content and } \\
\text { design }\end{array}$ & $\begin{array}{l}\text { support } \\
\text { quality }\end{array}$ & $\begin{array}{l}\text { techonological } \\
\text { factors }\end{array}$ & usefulness \\
\hline Alpha Cronbach & 0.635 & 1.000 & -0.179 & 0.813 & 0.882 & 0.863 & 0.822 \\
\hline
\end{tabular}

The average amount of variance (AVE) to assess discriminant validity results were higher than 0.50 , according to Fornell-Larcker (1981) criteria.

Table 2. Average variance extracted

\begin{tabular}{llllllll}
\hline & academic goal & dropout & learning style & $\begin{array}{l}\text { quality of } \\
\text { online course } \\
\text { content and } \\
\text { design }\end{array}$ & $\begin{array}{l}\text { support } \\
\text { quality }\end{array}$ & $\begin{array}{l}\text { techonological usefulness } \\
\text { factors }\end{array}$ \\
\hline $\begin{array}{l}\text { Average } \\
\text { variance } \\
\text { extracted }\end{array}$ & 0.581 & 1.000 & 0.329 & 0.598 & 0.740 & 0.609 & 0.655 \\
\hline
\end{tabular}

The Coefficient of Determination (R2) analysis to measure the accuracy of the model was performed to measure the variance proportion of the dependent (dropout) variable. The rates found for the independent variables (Usefulness, information failure, and system failure) were close to 0.50 , showing that the model's inputs can explain approximately half of the observed variation.

Table 3. Coefficient of determination (R2)

\begin{tabular}{lllll}
\hline R2 & academic goal & dropout & learning style & usefulness \\
\hline R2 & 0.108 & 0.105 & 0.049 & 0.438 \\
Adjusted R2 & 0.105 & 0.092 & 0.046 & 0.437 \\
\hline
\end{tabular}

Multicollinearity or intercorrelations were tested among predictors. The results show a lack of multicollinearity issues. All the variation inflation factors (VIF) suggested by Tabachnick and Fidell (2012) were less than 0.90.

Table 4. Correlation among predictors

\begin{tabular}{|c|c|c|c|c|c|c|c|}
\hline & academic goal & dropout & $\begin{array}{l}\text { information } \\
\text { failure }\end{array}$ & learning style & $\begin{array}{l}\text { support } \\
\text { quality }\end{array}$ & system failure & usefulness \\
\hline academic goal & 1.000 & 0.183 & 0.313 & -0.032 & 0.325 & 0.355 & 0.323 \\
\hline dropout & 0.183 & 1.000 & 0.296 & 0.091 & 0.211 & 0.224 & 0.171 \\
\hline $\begin{array}{l}\text { information } \\
\text { failure }\end{array}$ & 0.313 & 0.296 & 1.000 & 0.071 & 0.730 & 0.811 & 0.726 \\
\hline learning style & -0.032 & 0.091 & 0.071 & 1.000 & 0.103 & 0.042 & 0.098 \\
\hline $\begin{array}{l}\text { support } \\
\text { quality }\end{array}$ & 0.325 & 0.211 & 0.730 & 0.103 & 1.000 & 0.794 & 0.661 \\
\hline system failure & 0.355 & 0.224 & 0.811 & 0.042 & 0.791 & 1.000 & 0.696 \\
\hline usefulness & 0.323 & 0.171 & 0.726 & 0.098 & 0.661 & 0.696 & 1.000 \\
\hline
\end{tabular}




\subsection{Sample Characteristics}

Gender balance was pursued and achieved: $49.3 \%$ of the respondents were women, and $49.73 \%$ were men, and $1.4 \%$ decided not to answer this question. $73.7 \%$ of the students were between 30 and 40 years old.

The majority of the respondents were from the southwest region $(60 \%)$ and registered in corporate management (47.34\%). Most of the respondents (59.83\%) had already taken more than one online course, and their responses show experience with the online environment. For $34.7 \%$ of the respondents, the quality experienced by online learning is better than the one offered at in-person courses. However, $37.1 \%$ were not sure, and $28.2 \%$ disagreed with this perception.

\section{Analysis and Discussion}

All variables directly related to the dropout decision did not present a representative correlation, confirming previous research. However, the Support Quality variable included in the model as a moderator variable had a high correlation with the constructs Information Failure (0.73), System Failure (0.794), and Perceived Usefulness (0.661). This result ratified experts' opinion, which pointed out the relevance of the Support Quality effect by professors and tutors to the students' perception of the course's Usefulness and practicality in their professional lives. It also noted the quality of this support on the perception of the difficulty in using the system (System Failure) and the overall perception of course content quality (Information Failure).

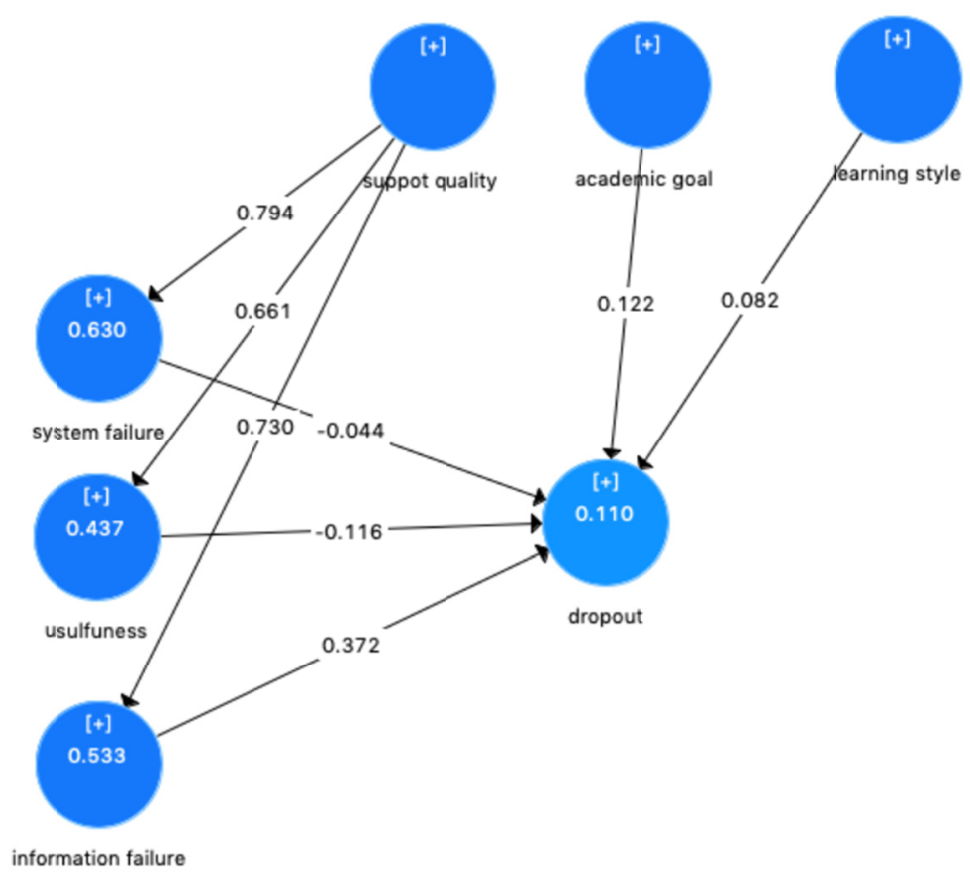

Figure 3. Coefficients in framework

This discussion brought a new contribution to the dropout analysis because it suggested that support quality had a strong influence on system failure, information failure, and perceived Usefulness and not directly on dropout decision. The survey confirmed these hypotheses (H6, H7, H8).

The correlation between the Brazilian learning style and dropout was not confirmed. That does not mean that there are no differences between Brazilians and international students' learning styles. To be sure of that, it would be necessary to study a representative group of different nationalities. However, this sample did not confirm the hypothesis.

The importance of support quality demonstrated in this survey reinforces Nerguizina et al. (2010) statement, who say that the main variables of e-learning are human beings and tutors. They still have an essential role in engaging and motivating students, even though it is based on technological tools.

The support quality may be related to practical assistance with technology and computer (Hart, 2012) and to 
pedagogical support influencing how learning and teaching should be delivered considering interaction, collaboration, and communication between learners and teachers in the e-learning environment (Masoumi \& Lindström, 2012). Although technical support does not predict persistence, dropout students present a lower satisfaction rate with support services (Ivankova \& Stick, 2007).

Previous studies (Kember, 1989; Rovai, 2003; Willing \& Johnson, 2004; Holder, 2007; Park, 2007; Park \& Choi, 2009; Hart, 2012; Lee, Choi, \& Kim, 2013) confirmed the importance of course content and design, preventing from information failure. Information failure has a high correlation with student satisfaction, and inaccurate or irrelevant information increases dissatisfaction and is associated with drop out (Chee-Wee Tan, Benbasat, \& Centefelli, 2016). These findings validate Willging and Johnson (2004), and Levy's (2007) studies.

\section{Conclusions}

E-learning in the world became a fundamental methodology of learning. It gives people the chance to update their knowledge, develop an understanding of new things occurring abroad, and become more competitive.

In Brazil, it also became a phenomenon. There are more students registered in online classes than in mortar-and brick classes. However, for Brazilian society, the institutions, and the students, it is a new experience. There is still little comprehension of how it works, the level of difficulty, the best technological platform to offer, the depth of content, and its design more appropriate.

This study's significant contribution was the use of the construct support quality as a moderator variable affecting three constructs already identified in previous studies as relevant in students' course evaluation. This discussion on the dropout analysis suggested that support quality had a strong influence on system failure, information failure, and perceived Usefulness and not directly on dropout decision.

The online course environment's quality support is determinant to minimize difficulty that students face and evaluate the course quality. That conclusion reinforced Souza's study (2009). Her work concludes that factors such as the quality of interaction between students and teachers and information quality are the leading causes of dropping out.

Due to the little experience, dropout is a definite concern. The model "one fits all" is not adequate. Some people talk about artificial intelligence in learning that would offer a methodology appropriate for each student, allowing him to develop knowledge at his own pace.

Brazil has 210 million people and is the fifth extensive territory in the world. There is also a gap in education that makes e-learning a vital tool to attend the whole population all over the country.

Based on this study, it is recommended that institutions focus on the quality of their e-learning platform, the quality of the course content and design focusing on the Usefulness, competencies, and practice. It is also necessary to invest in support quality to help students overcome their eventual lack of goal commitment and weakness of their learning styles.

\section{Practical Implications}

As an academic contribution, this study gathered students and expert opinions in the same research considering the two different points of view. That combination helped to emphasize the importance of some factors to dropout decisions.

This study also innovated gathering theories from four different fields: Individual characteristics (locus of control, goal commitment, and learning style); Institution support (social integration and support quality); The impact of Information System Failures (Information and System Failure) that has been studied in an e-commerce website, and Technology Acceptance Model (Usefulness, Ease of Use and Subjective Norms).

Another significant contribution in this study was using the construct support quality as a moderator variable affecting three previously identified constructs in previous studies as relevant in students' course evaluation. The relationship between support quality to the perception of system failure, information quality, and Usefulness is relevant. It highlights the importance of the support quality to balance any possible inefficiency or student difficulty with the platform, content quality, and students' perception of the course's Usefulness for their lives.

Students demand frequent attention from professors and tutors. This support indirectly influences the dropout decision, influencing the perception of course practicality, quality of the system, and content.

It is not possible to state that this need for student support is due to Brazilian cultural characteristics. However, with the proliferation of online courses in Brazil, the observance of this need for support quality becomes relevant to minimize the dropout rate. 
E-learning in Brazil is still a new business, and institutions have not yet found the best format and density of content and design and the best tools to keep students motivated.

There are common factors affecting students' decision to persist or drop out, showing the relevance of those factors. Factors such as the course content and course design, the Usefulness of the content to student's job activities, the institutions' support on content, and technical issues are of great importance in students' evaluation.

As already stated by Nerguizina et al. (2010), even though e-learning occurs on technological tools, human beings and tutors have an essential role in engaging and motivating students. The findings confirm Rothkrantz (2017) theory that monitors and professors can impact students' achievement, motivating, and creating good emotions in them in an online environment.

\section{Limitations}

This need for support may be related to Brazilians' characteristics discussed earlier, along with the study. It would be necessary to test the hypothesis in another country with a different culture to generalize these findings.

Brazilians are collectivists and have a low level of long-term orientation, usually avoiding uncertainty, not taking risks. E-learning quality and validity is uncertain and can cause distrust. Besides that, working alone is not part of Brazilian culture. They need to interact, socialize. Brazilians have a reduced orientation for action and organizational planning, and they manage time inefficiently, one of the requisites of the online environment.

Interpersonal relationships with peers can help students to build self-esteem. However, e-learning can be a lonely experience, and integration in the academic community may become difficult.

Brazilian culture defends hierarchical differences based on teacher and peer support. Onsite classes are more likely to meet the needs of their learning style.

Although the relation between culture and learning style has been discussed, Learning Style did not correlate with dropout. The sample was not adequate to prove that there is a difference in learning styles in different countries. The study occurred in only one country and one institution. It would be valuable to test the model in classes where the number of international students is high. It would probably be possible in well-known institutions where the courses are in English, a more disseminated language.

This concern for learning style can be valuable for institutions, considering that e-learning is an intense globalization process.

The survey focused on students in short-term courses, eight weeks at the most, that today represent most of Brazil's online courses.

However, in 2018, the number of online undergraduate courses offered in Brazil accounted for $53 \%$ of the total undergraduate courses provided according to the census that registered a low completion rate of $37 \%$ (Censo, 2018). As the number of undergraduate courses online has already surpassed the number of undergraduate courses in person, a further study focusing on this type would be recommended.

Theoretically, as an undergraduate course requires the student to complete all the disciplines to acquire the diploma, it could be assumed that the dropout rate would be lower. However, the statistics have not proved this expectation.

Another suggestion for further studies would be to analyze the dropout rate, specifically in longer-term courses like the Graduate Specialization (MBA) courses, to test the validity of the correlations encountered. The demand for MBA courses is increasing, and they are of great interest to the institutions because they generate more revenue.

\section{References}

Almeida, A. C. (2014). A Cabeça do Brasileiro (7th ed.). Publisher Record.

Aparicio, M., Bacao, F., \& Oliveira, T. (2016a). An e-Learning Theoretical Framework. Educational Technology \& Society, 19, 292-307.

Aparicio, M., Bacao, F., \& Oliveira, T. (2016b). Cultural impacts on e-learning systems' success. Internet and Higher Education, 31, 58-70. https://doi.org/10.1016/j.iheduc.2016.06.003

Aparicio, M., Bacao, F., \& Oliveira, T. (2017). Grit in the path to e-learning success. Computeres in Human Behavior, 66, 388-399. https://doi.org/10.1016/j.chb.2016.10.009

Bandura, A. (2001). Social Cognitive Theory: An Agentic Perspective. Annual Reviews Psychol, 52, 1-26. 
https://doi.org/10.1146/annurev.psych.52.1.1

Barros, B. T., \& Prates, M. A. S. (1996). O Estilo Brasileiro de Administrar. São Paulo: Atlas.

Bean, J. P. (1979). Dropouts and Turnover: Tae Synthesis and Test of a Causal Model of Student Attrition (pp. 12-54). Paper presented at the Annual Meeting of the American Educational Research Association, April 8. https://doi.org/10.1007/BF00976194

Bean, J. P., \& Eanton, S. B. (1995). An approach/avoidance behavioral model of college student attrition. Research in Higher Education, 36(6), 617-645. https://doi.org/10.1007/BF02208248

Bunn, J. (2004). Student Persistence in a LIS Distance Education Program. Australian Academic \& Research Libraries, 35(3), 253-269, https://doi.org/10.1080/00048623.2004.10755275

Cenfetelli, R. T., \& Schwarz, A. (2011). Identifying and testing the Inhibitors of Technology Usage Intentions. Information Systems Research, 22(4), 808-823. https://doi.org/10.1287/isre.1100.0295

Chee-wee Tan, B., \& Centefelli. (2016). An Exploratory Study of the Formation and Impact of Electronic Service Failures. Management Information System Quarterly, 1-67.

Chu, R. A., \& Wood Jr., T. (2008). Cultura organizacional brasileira pós-globalização: global ou local? RAP-Rio de Janeiro, 42(5), 969-991. https://doi.org/10.1590/S0034-76122008000500008

DaMatta, R. D. (1984). O que faz o brasil, Brasil? Rio de Janeiro: Rocco.

Davis, F. D. (1980). A Technology Acceptance Model for Empirically Testing New End-User Information Systems: Theory and Results (pp. 1-291). Doctoral dissertation, Sloan School of Management, Massachusetts Institute of Technology.

Davis, F. D. (1989). Perceived Usefulness, Perceived Ease of Use, and User Acceptance of Information Technology. MIS Quarterly, 13(3), 319-340. https://doi.org/10.2307/249008

Davis, F. D., Bagozzi, R. P., \& Warshaw, P. R. (1989). User acceptance of computer technology: A comparison of two theoretical models. Management Science, 35, 982-1003. https://doi.org/10.1287/mnsc.35.8.982

DeLone, W. H., \& McLean, E. R. (2003). The DeLone and McLean model of information systems success: A ten-year update. Journal of Management Information Systems, 19(4), 9-30. https://doi.org/10.1073/pnas.0914199107

Duckworth, A. L., Peterson, C., Matthews, M. D., \& Kelly, D. R. (2007). Grit: Perseverance and passion for long-term goals. Journal of Personality and Social Psychology, 92(6), $1087-1101$. https://doi.org/10.1037/0022-3514.92.6.1087

Eskreis-Winkler, L. S., Elizabeth, P. B., Scott, A., \& Duckworth, A. L. (2014). The grit effect: predicting retention in the military, the workplace, school, and marriage. Frontiers in Psychology, 5, 1-12. https://doi.org/10.3389/fpsyg.2014.00036

Fornell, C., \& Larcker, D. F. (1981). Evaluating Structural Equation Models with Unobservable Variables and Measurement Error. Journal of Marketing Research, 18(1), 39-50. https://doi.org/10.1177/002224378101800104

Garrison, D. R. (1987). Researching dropout in distance education. Distance Education, 8(1), 95-101. https://doi.org/10.1080/0158791870080107

Guild, P. (1994). The culture/learning style connection. Educational Leadership, 51(8), 16-21.

Guri-Rosenblit, S. (2005). Distance education and e-learning: Not the same thing. Higher Education, 49, 467-493. https://doi.org/10.1007/s10734-004-0040-0

Hart, C. (2012). Factors Associated with Student Persistence in an Online Program of Study: A Review of the Literature. Journal of Interactive Online Learning, 11(1).

Haydarov, R., Moxley, V., \& Anderson, D. (2013). Counting Chickens before they are hatched: An Examination of student retention, graduation, attrition, and dropout measurement validity in an online Master's environment. Journal of College Student Retention: Research, Theory \& Practice, 14(4), 429-449. https://doi.org/10.2190/CS.14.4.a

Hofstede, G. (1980). Culture's consequences: International differences in work-related values. Beverly Hills, CA: Sage.

Hofstede, G. (2001a). Adoption of communication technologies and national culture. Systèmes d'Information et 
Management, 6(3), 55-74.

Hofstede, G. (2001b). Culture's Consequences: Comparing Values, Behaviours, Institutions and Organizations Across Nations. Thousand Oaks: Sage.

Hofstede, G., Hilal, A. V., Garibaldi de, M., Sigmar, T. B., \& Vinken, H. (2010). Comparing Regional Cultures within a Country: Lessons from Brazil. Journal of Cross-Cultural Psychology, 41(3), 336-352. https://doi.org/10.1177/0022022109359696

Holder, B. (2007). An investigation of hope, academics, environment, and motivation as predictors of persistence in higher education online programs. Internet and Higher Education, 10, 245-260. https://doi.org/10.1016/j.iheduc.2007.08.002

Holtbrügge, D., \& Mohr, A. (2010). Cultural Determinants of Learning Style Preferences. Academy of Management Learning \& Education, 9(4), 622-637. https://doi.org/10.5465/amle.9.4.zqr622

Ivankova, N. V., \& Stick, S. L. (2007). Students' persistence in a distributed doctoral program in educational leadership in higher education: A mixed methods study. Research in Higher Education, 48(1), 93-135. https://doi.org/10.1007/s11162-006-9025-4

Kember, D. (1989). A Longitudinal-Process Model of Drop-Out from Distance Education. Journal of Higher Education, 60(3), May/June. https://doi.org/10.2307/1982251

Kerka, S. (1996). Distance learning, the Internet and the World Wide Web. ERIC Digest (ERIC Document Reproduction Service No. ED395214). Retrieved July 14, 2002, from http://www.ed.gov/databases/ERIC_Digests/ ed395214.html

Kizilcec, R. F., \& Halawa, S. (2015). Attrition and Achievement Gaps in Online Learning. Proceedings of the Second ACM Conference on Learning@Scale - L@S 15.1-11.https://doi.org/10.1145/2724660.2724680

Lee, Y., Choi, J., \& Kim, T. (2013). Discriminating factors between completers of and dropouts from online learning courses. British Journal of Educational Technology, 44(2), 328-337. https://doi.org/10.1111/j.1467-8535.2012.01306.x

Lepper, M. R. (1988). Motivational Considerations in the Study of Instruction. Cognition and Instruction, 5(4), 289-309. https://doi.org/10.1207/s1532690xci0504_3

Levy, Y. (2007). Comparing dropouts and persistence in e-learning courses. Computers \& Education, 48, 185-204. https://doi.org/10.1016/j.compedu.2004.12.004

Masoumi, D., \& Lindstrom, B. (2012). Quality in e-learning: A framework for promoting and assuring quality in virtual institutions. Journal of Computer Assisted Learning, 28(1), $27-41$. https://doi.org/10.1111/j.1365-2729.2011.00440.x

Moore, J. (2014). Effects of Online Interaction and Instructor Presence on Students' Satisfaction and Success with Online Undergraduate Public Relations Courses. Journalism \& Mass Communication Educator, 69(3), 271-288. https://doi.org/10.1177/1077695814536398

Motta, F., Prestes, C., \&Alcadipani, R. (1999). Jeitinho brasileiro, controle social e competição. Rev. adm. Empresas, 39(1), 6-12. https://doi.org/10.1590/S0034-75901999000100002

Nerguizina, V., Mhiri, R., \& Saad, M. (2010). Active e-learning Approach for e-business. International Journal of e-Business Management, 5(1).

Packham, G., Jones, G., Miller, C., \& Thomas, B. (2004). E-learning and retention: Key factors influencing student withdrawal. Education \& Training, 46(6/7), 335-342. https://doi.org/10.1108/00400910410555240

Park, J. (2007). Factors related to learner dropout in online learning. In F. M. Nafukho, T. H. Chermack \& C. M. Graham, (Eds.), Proceedings of the 2007 Academy of Human Resource Development Annual Conference (pp. 251-258).

Park, J. H., \& Choi, H. J. (2009). Factors influencing adult learners' decision to drop out or persist in online learning. Educational Technology \& Society, 12(4), 207-217.

Pascarella, E. T., \& Terenzini, P. T. (1980). Predicting Freshman Persistence and Voluntary Dropout Decisions from a Theoretical. The Journal of Higher Education, 51(1), 60-75. https://doi.org/10.1080/00221546.1980.11780030

Pasquali, L., \& Alves, A. R. (2004). Validação do Portraits Questionnaire - PQ de Schwartz para o Brasil. Avaliação Psicológica, 3(2), 73-82. 
Ringle, C. M., Wende, S., \& Becker, J. (2015). SmartPLS 3. Bonningstedt: SmartPLS. Retrieved from http://www.smartpls.com

Rovai, A. P. (2003). In search of higher persistence rates in distance education online programs. Internet and Higher Education, 6, 1-16. https://doi.org/10.1016/S1096-7516(02)00158-6

Schwartz, S. H., \& Tamayo, A. (2012). Estrutura Motivacional dos Valores Humanos Psicologia: teoria e pesquisa (pp. 228-348). revistaptp.unb.br.

Souza, C. A. N. (2009). Um estudo sobre as principais causas da evasão na educação a distância - EAD. Dissertação Mestre em Administração Pública da EBAPE - FGV, Março.

Spady, W. G. (1971). Dropouts from higher education: Toward an empirical model. Interchange, 2(3), 38-62. https://doi.org/10.1007/BF02282469

Strom, R. E., \& Savage, M. W. (2014). Assessing the Relationships Between Perceived Support from Close Others, Goal Commitment, and Persistence Decisions at the College Level. Journal of College Student Development, 55(6), 531-547. https://doi.org/10.1353/csd.2014.0064

Tabachnick, B. G., \& Fidell, L. S. (2012). Chapter 13 principal components and factor analysis. Using multivariate statistics. London: Pearson.

Teixeira, M. L. M., Sambiase, M. F., Janik, M., \& Bilsky, W. (2014). Peculiaridades da Estrutura de Valores Básicos dos Brasileiros (Characteristic Features of Brazilians' Basic Values). Revista Psicologia: Organizações e Trabalho, 14(2), 139-152.

Teperino, A. S., Guelfi, A. C., Kipnis, B., Longo, C., Lopes, C. M. B., Lima, E. D. B. d., ... Tarcilena, P. C. (2006). Educação a distância em organizações públicas. Mesa-redonda de pesquisa-ação (p. 200). Brasília - ENAP. ISBN: 85-256-0054-7.

Tinto, V. (1975). Dropout from Higher Education: A Theoretical Synthesis of Recent Research. Review of Educational Research, 45, 89-125. https://doi.org/10.3102/00346543045001089

Tynan, B., \& James, R. (2013). Special theme: Openness in higher education Distance education regulatory frameworks: Readiness for openness in Southwest Pacific/South East Asia region nations. Open Praxis, 5(1), 91-97. https://doi.org/10.5944/openpraxis.5.1.31

UNESCO Institute for Statistics data. (2020). Global monitoring of school closures caused by COVID-19. Retrieved April 6, 2020, from https://en.unesco.org/covid19/educationresponse

Willging, P. A., \& Johnson, S. D. (2004). Factors that influence students' decision to dropout of online courses. Journal of Asynchronous Learning Network, 8(4), 105-118. https://doi.org/10.24059/olj.v8i4.1814

\section{Copyrights}

Copyright for this article is retained by the author, with first publication rights granted to the journal.

This is an open-access article distributed under the terms and conditions of the Creative Commons Attribution license (http://creativecommons.org/licenses/by/4.0/). 